\title{
Derleme https://doi.org/10.33484/sinopfbd.537820 Gıdalarda Aflatoksin Düzeylerinin Belirlenmesinde Kullanılan Analiz Yöntemleri
}

\author{
Merve AÇU ${ }^{a}$, Özgül ÖZDESTAN OCAK ${ }^{b}$ \\ a İzmir Gıda Kontrol Laboratuvar Müdürlüğ̈̈, Bornova-İzmir \\ ${ }^{\boldsymbol{b}}$ Ege Üniversitesi, Mühendislik Fakültesi, Gıda Mühendisliği Bölümü, 35100, Bornova-İzmir
}

$\ddot{\mathbf{O} z}$

Aflatoksinler kuru meyveler, yağlı kuru meyveler, baharatlar, tahıllar, süt ve süt ürünleri ve hayvan yemlerinde yaygın olarak bulunabilen mikotoksinlerdendir. Aflatoksinler diğer mikotoksinler gibi, bu ürünlerde hasat öncesi tarlada, hasat zamanı veya hasat sonrası uygun olmayan depo koşullarında toksin üreten fungusların gelişmesiyle ortaya çıkmaktadırlar. Ayrıca işleme ve depolama gibi çeşitli aşamalarda da kontaminasyon riski söz konusudur ve bu durum oldukça sorun oluşturmaktadır. Aflatoksinlerin karaciğer hastalıkları (hepatatoksik, hepatokarsinojenik), kanserojen ve teratojenik etkiler, kanamalar (bağırsaklar, böbrekler), bağışıklık sistemine baskı gibi sağlık üzerine olumsuz etkileri bulunmaktadır. Gıda ve yemlerde bulunan aflatoksinlerin belirlenmesinde kullanılan birçok metot vardır. Aflatoksin analizlerinde ince tabaka kromatografisi, kapiler elektroforez, ELISA, yüksek basınçlı sıvı kromatografisi, gaz kromatografisi ve kromatografik metotların kütle spektroskopisi ile birlikte kullanımı gibi metotlar kullanılmaktadır. Kromatografik metotların kütle spektroskopisi ile birlikte kullanımı ile daha düşük ölçüm limitlerine ulaşılabilmektedir. Bu nedenle son zamanlarda bu yöntemler ön plana çıkmaktadır. Bu derlemede gıdalarda aflatoksinlerin belirlenmesinde kullanılan analiz yöntemleri ve bu yöntemler ile ilgili son gelişmeler üzerinde durulacaktır.

Anahtar sözcükler: Aflatoksin, mikotoksin, HPLC, LC-MS/MS

\section{The Methods of Analysis Used in the Determination of Aflatoxin Levels in Food}

\begin{abstract}
Aflatoxins are mycotoxins which are widely found in dry fruits, oily dried fruits, spices, cereals, milk and dairy products and animal feed. These occur in the development of toxinproducing fungi in pre-harvest field, during harvest time, or under unsuitable storage conditions after harvest. Also, there is a risk of contamination at various stages such as processing and storage. Aflatoxins have adverse effects on health such as liver diseases (hepatotoxic, hepatocarcinogenic), carcinogenic and teratogenic effects, hemorrhages (intestine, kidney etc.) and pressure on the immune system. There are a number of methods used to identify aflatoxins found in food and feed. These include thin layer chromatography, capillary electrophoresis, ELISA, high pressure liquid chromatography, gas chromatography, and mass spectroscopy of chromatographic to analyze aflatoxins. Lower measurement limits can be achieved by using chromatographic methods with mass spectroscopy. For this reason, these methods have recently
\end{abstract}

\footnotetext{
${ }^{*}$ Sorumlu Yazar: : ORCID ID: orcid.org/ 0000-0002-8782-762X

Received: 10.03 .2019

e-mail: acumerve88@gmail.com

Accepted: 30.10 .2019
} 
come into prominence. This review will focus on the methods of analysis and recent developments in the identification of aflatoxins in food.

Key words: Aflatoxin, mycotoxin, HPLC, LC-MS/MS

\section{Giriş}

Mikotoksinler, yem ve gidalarda fungus türleri tarafindan sentezlenen metabolik ürünler olup, bunlarla beslenen havyan ve insanlarda mikotoksikozislere sebep olan toksik maddelerdir [1]. İnsan ve hayvan sağlığı üzerine olan farklı etkileri ile aflatoksinler, fumonisinler, okratoksinler, zearalenonlar ve trikotesenler gibi günümüzde bilinen 400'ü aşkın toksin bulunmaktadır. Hasat öncesi tarlada, hasat zamanı veya hasat sonrası uygun olmayan depo koşullarında toksin üreten fungusların gelişmesiyle ortaya çıkmaktadırlar [2; 3].

Kuru meyveler, misır, buğday, arpa, pirinç, fındık, fıstık / yer fıstığı, süt ve peynir gibi gidalar mikotoksinlerle kontamine olabilirler. Çeşitli fiziksel, kimyasal ve biyolojik faktörlerin de mikotoksin oluşumu üzerine etkileri vardır. $\mathrm{Bu}$ toksinler belirli nem ve sicaklık koşullarında küfler tarafından oluşturulurlar $[2 ; 3]$.

En önemli mikotoksin üreticisi küfler Aspergillus, Penicillium, Fusarium, Alternaria ve Claviceps türlerine aittir [4; 5].En yaygın mikotoksin türleri de aflatoksinler, okratoksin-A, fumonisinler, deoksinivalenol, T-2 toksin, zeralenon ve patulindir [6]. Aflatoksinler Aspergillus flavus, A. parasiticus ve A. nomius tarafından üretilen toksik metabolitlerdir. Aflatoksin B1, B2, G1, G2 olmak üzere başlıca 4 çeşit aflatoksin türü vardır. Aflatoksin M1 ise süt ve süt ürünlerinde en fazla rastlanan toksindir ve 'Süt Toksini' olarak da bilinmektedir. Aflatoksin B1 yemler aracılığ́ ile süt hayvanına geçer, vücutta metabolize olur ve M1 şekline dönüşüp süt ürünleri aracılığıyla insanlara geçer [6]. Toksisite sıralaması Aflatoksin $\mathrm{B} 1>\mathrm{M} 1>\mathrm{G} 1>\mathrm{B} 2>\mathrm{G} 2$ şeklindedir.

Aflatoksin ile kontaminasyon riski en yüksek olan gıdalar arasında kuru incir, yer fistığı, Antep fistığı, misır, baharatlar, çiğ süt v.b. yer almaktadır. Aflatoksinler metanol, kloroform ve asetonda çözünür ancak su ve petrol eterinde çözünmezler [7; 8]. Aflatoksin B1 ve B2 ultraviyole 1 ş1k altında mavi floresans; aflatoksin G1 ve G2 ise yeşil floresans verirler. Gıdaları ekimden tüketime kadar her aşamada kontamine edebilirler [9; 10; 11]. Aflatoksin B1, B2, G1, G2 ve M1'in kimyasal yapıları Şekil 1'de görülmektedir. 


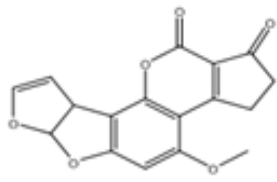

Aflatoksin Bl

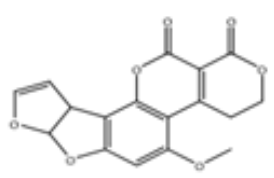

Aflatoksin Gl

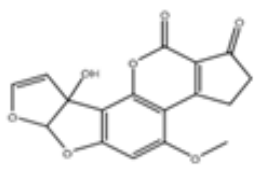

Aflatoksin Ml

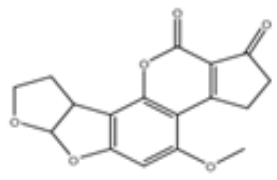

Aflatoksin B2

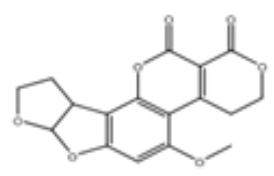

Aflatoksin G2
Şekil 1. Aflatoksin B1, B2, G1, G2 ve M1 [12]

Genotoksik etkilerinin yanında aflatoksin, okratoksin ve fumonisin gibi toksinlerin kanserojenik olması ve bu hayvanlardan elde edilen besinlerin de insanlar tarafindan tüketilmesi ile de oluşabilecek sorunlar nedeniyle sağlık açısından son derece önemlidir. Aflatoksinlerin karaciğer hastalıkları, kanserojen ve teratojenik etkiler, çeşitli kanamalar (bağırsaklarda, böbreklerde v.b.) ve bağışıklık sistemine baskı gibi sağlık üzerine çeşitli olumsuz etkileri bulunmaktadır [8].

Gıdalar için Türk Gıda Kodeksi 2011 Bulaşanlar Yönetmeliği, yemler için de Yemlerde İstenmeyen Maddeler Hakkında Tebliğ No: 2014/11 yer almaktadır. Söz konusu tebliğlerde ilgili matriksler için bulunan maksimum limitlere göre değerlendirme yapılmaktadır.

Aflatoksin analizleri için farklı yöntemler bulunmaktadır. İnce tabaka kromatografisi, kapiler elektroforez, ELISA, yüksek basınçlı sıvı kromatografisi, gaz kromatografisi ve kromatografik metotların kütle spektroskopisi ile birlikte kullanımı gibi metotlar aflatoksin analiz yöntemleri arasında yer almaktadır.

$\mathrm{Bu}$ derlemenin amacı gidalarda aflatoksinlerin belirlenmesinde kullanılan adı geçen analiz yöntemleri ve kullanılan yöntemlerdeki son gelişmeler hakkında bilgi vermektir.

\section{Aflatoksin Analiz Yöntemleri}

Aflatoksin analizlerinde daha önce bahsedilen çeşitli yöntemler kullanılmaktadır. Günümüzde bu yöntemlerin arasında en yaygın olarak enstrümental olanları kullanılmaktadır. Son zamanlarda da kromatografik metotların kütle spektroskopisi ile birlikte kullanımı ön plana çıkmaktadır.

- $\quad$ Ince Tabaka Kromatografisi (TLC)

- $\quad$ Kapiler Elektroforez

- $\quad$ ELISA (Enzyme-Linked

Immunosorbent Assay)

- $\quad$ Yüksek Basınçlı (Performans) Sıv1 Kromatografisi (HPLC)

- $\quad$ Gaz Kromatografisi (GC) 
- Kromatografik Metotların Kütle Spektroskopisi ile Birlikte Kullanımı (LCMS/MS, GC-MS/MS gibi) [8].

\section{İnce Tabaka Kromatografisi (TLC)}

Bu teknikte tabaka üzerinde hareketli fazın ilerlemesi kapilarite sayesinde olmaktadır. Ayrım mekanizması adsorpsiyon, partisyon, iyon değişimi etkilerinin iki veya daha fazlasina dayanmaktadır. İnce tabaka kromatografisi ile kantitatif analizler önceleri plakadan bantların elüe edilmesini takiben spektrofotometre vb. ile yap1lırken 1970'li y1llarda plaka üzerinden doğrudan tayin yapılan densitometrik teknikler geliştirilmiştir. 1980'li yıllarda Yüksek Performanslı TLC (HPTLC) plakaları geliştirilmiştir. Son yıllarda solventin sabit faz üzerinden basınçla ve dolayısıyla daha hızlı geçirildiği OPTLC (Over Pressure TLC) tekniği ve santrifüj ile hızlandırılarak geçirildiği dairesel bir preparatif TLC tekniği geliştirilmiştir $[13 ; 14 ; 15]$. İnce tabaka kromotografisi ile yapılan mikotoksin analizlerinde analitik işlem basamakları; örnekleme, ekstraksiyon ve ekstrakt temizleme, yoğunlaştırma, kromatografik ayırım, kalitatif ve kantitatif tayin ve doğrulama testleri şeklindedir [8]. TLC yerini HPLC metotlarının alması dolayısıyla artı çok fazla kullanılmamaktadır. Bu metot çok fazla solvent kullanımı, yoğun prosedürleri gerektirir. Bununla beraber çeşitli örnekleri hızla taramak için kullanılabilir [16]. Ekstraksiyon ve yoğunlaştırma aşamalarından sonra kromatografi işlemi söz konusudur [17; 18]. TLC ile aflatoksin analizlerinde aflatoksinlerin matrikslerden ekstraksiyonunda başlica kloroform:su, metanol:su ve asetonitril:su ekstraksiyonu kullanılır. Yoğunlaştırma işlemi rotary evaporatörde yapılır. Kloroformla yıkanan aflatoksinlerin alınması için azot gazı altında buharlaştırma uygulanır [19;15]. Van Egmond ve ark. [17] TLC'nin aflatoksinler için tipik uygulamasını gerçekleştirmiştir. Aflatoksin M1'in trifloroasetik asit ile reaksiyonu sonucu analizini yapmışlardır. Yöntemde kloroform-metanol-asetik asit-su karışımı kullanmışlardır [17; 18].

\section{Kapiler Elektroforez}

Bileşenlerin etkin ayrılması elektriksel bir alanda yük ve kütle migrasyonu esasına dayanır. Kapiler elektroforezin hassas floresanslı saptama yöntemleriyle kombinasyonu aflatoksinler için kullanılabilmektedir [16; 20]. Örnekler ince, dayanıklı kapilerlerden elektrik akımı ile geçirilmektedir. $\mathrm{Bu}$ proses bileşiklerin elektrik yüklerine göre ayrılmasını sağlamakta, geleneksel yöntemlerde olduğu gibi herhangi bir çözücü 
kullanılmamaktadır [21]. 1998'den itibaren Maragos kapiler elektroforez yöntemini deoksinivalenol toksininde de çalışmıştır.

\section{Elisa}

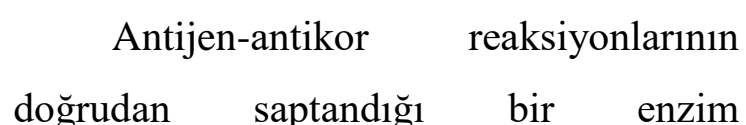
immunoassay yöntemidir. Mikotoksinlerin antijenik özellik göstermeleri için bir protein ya da polipeptit zincirine bağlanması gerekmektedir. Okratoksin, patulin ve penisilik asit gibi reaktif gruplara sahip mikotoksinler doğrudan bağlanma reaksiyonları gösterirler. Buna karşın aflatoksin ve trikotesenleri kapsayan birçok toksin ise reaktif gruplara sahip değildir ve bu nedenle reaktif karboksil veya başka bir grubun öncelikle toksin molekülüne bağlanması gerekmektedir [8; 22]. Antijenler antikorlara hidrojen bağları, eletrostatik etkileşimler, hidrofobik etkileşimler ve van der Wals güçleri gibi kovalent olmayan bağlarla geri dönüşümlü olarak bağlanırlar. ELISA yönteminde de ilk aşama örneğe uygulanacak olan ekstraksiyon işlemidir. ELISA yöntemi ile yapilan mikotoksin analizlerinde son yıllarda sep-pak kartuşlar kullanılmaktadır. $\mathrm{Bu}$ işlem 3 aşamada gerçekleşmektedir. Birinci aşamada örnek kartuşa ilave edilir. Daha sonra uygun bir solvent kullanılarak örnekte bulunabilecek kirlilik maddeleri ortamdan uzaklaştırılır ve son olarak uygun bir çözücü kullanılarak toksin kartuştan alınır. ELISA yönteminin değişik mikotoksin analizlerinde kullanılması, değişik mikotoksinlere karşı spesifik antikor üretimine bağlıdır. $\mathrm{Bu}$ nedenle antikor üretimi için daha etkili yöntemlerin geliştirilmesine ihtiyaç duyulmaktadır [6; 23].

\section{HPLC}

HPLC yöntemi bir sıvıda çözünmüş bileşenlerin, bir kolon içerisinde bulunan genellikle katı bir destek üzerindeki sabit faz ile değişik etkileşimlere girmesi, kolon içinde değişik hızlarla hareket etmeleri sonucu, farklı zamanlarda bileşenlerin kolonu terk ederek birbirlerinden ayrılması temeline dayanır. Yaygin kullanılma sebepleri duyarlılığı, kantitatif tayinlere kolaylıkla uyarlanabilir olması, uçucu olmayan veya sicaklikla kolayca bozunabilen bileşiklerin ayrılmasına uygunluğudur. Doğal floresan olan aflatoksinler UV absorbsiyon, floresans ve MS dedektörü ile HPLC'de analiz edilebilmektedir [8; 16;24].

HPLC cihazı temel olarak pompa, enjeksiyon bloğu, kolon, dedektör kısımlarından oluşmaktadır. HPLC cihazında kullanılan kolonlar 4,5-5 $\mathrm{mm}$ iç çaplı ve 10-30 cm uzunluğunda, 5-10 $\mu \mathrm{m}$ sabit faz partikülleriyle paketlenmiş durumdadırlar. Kolonlar paslanmaz 
çelikten yapılmıştır. Kolon dolgu maddesi seçiminde, tanecik büyüklüğü, tanecik büyüklüğünün dağılımı, gözenek hacmi ve yüzey alanı gibi özellikler rol oynar. Sabit faz olarak genellikle gözenekli maddeler kullanılmaktadır. Kullanılan dolgu maddeleri silika ve alümina esaslıdır [25].

İdeal bir dedektör ise geniş bir konsantrasyon aralığında yüksek duyarlılığa, düşük gürültü seviyesine ve yüksek seçiciliğe sahip olmalıdır. Aflatoksinler hem normal hem de ters faz sistemlerde UV absorbsiyon, floresans ve MS dedektörü ile HPLC'de analiz edilebilmektedir.

HPLC ile yapilan mikotoksin çalışmalarında genellikle floresans dedektör kullanılmaktadır. Floresans dedektörde hücreden hareketli faz içerisinde çözünmüş halde bileşikler geçerken üzerine uzun dalga boyunda monokromatik 1şın gönderilir. Bileşik tarafından absorbe edilen bu ışın daha sonra başka dalga boyunda geri verilir. Floresans ölçümde bu emisyon analiz için değerlendirilir [25;8].

Sistem ekstraksiyon-IAC-cihaza enjeksiyon prensibine dayanır. Ekstraksiyonda metanol, asetonitril, aseton ve su gibi solventler kullanılmaktadır. Uygun solventler ile numunedeki aflatoksinler solvent kısmına geçirilerek süzüldükten sonra elde edilen süzüntü IAC'ye getirilir. İmmunoaffinite kolondan hazırlanan örnek geçirilir ve aflatoksinler burada tutuklanır. IAC saf su ile yıkanır, IAC'den metanol ile aflatoksinler ayrılır ve HPLC'ye verilir.

Çoğu mikotoksin uçucu değildir ve bu nedenle GC'de analize alınacaksa analiz için türevlendirilmelidir (OTA'nın ve DON'un türevlendirilerek GC'de analize alınması) [16; 26]. Garner ve ark. [27] HPLC'de çalıştığı toz baharat gibi ürünlerde aflatoksin analizinde immunoaffiniti kolonların gerekli olduğunu bildirmiştir.

82 adet işlenmiş tahıl örneğinde (ekmek, un, nişasta, irmik v.b.) modifiye metotlarla HPLC'de yapılan çalışmada 0,5 $\mu \mathrm{g} / \mathrm{kg}$ kadar düşük seviyelerde toplam aflatoksin içeren örneklerin analizi yapılabilmiştir. Ortalama geri kazanım oranı da toplam aflatoksin için \% 98 olarak belirtilmiştir [8].

73 adet Antep fistığı örneğinde HPLC'de yapılan çalışmada aflatoksin geri kazanım değerleri aflatoksin B1 için \% 80, aflatoksin B2 için \% 84, aflatoksin G1 için \% 81 ve aflatoksin G2 için ise \% 70 olarak belirlenmiştir. Aflatoksin anazilinde belirleme limiti (LOD) 0,001 ppb olarak belirtilmiştir [28]. 
Mikotoksin

Analizlerinde

Kromatografik Metotların Kütle

Spektroskopisi İle Birlikte Kullanımı

Kütle spektrumu, örnekteki bileşiklerin kolaylıkla hareket edebilen iyonlara (çoğunlukla pozitif) dönüştürülmesi ve bu iyonların kütle/yük oranına göre sıralanmasıyla elde edilir.

\section{Kütle Spektrometresi}

İyon kaynağı, kütle analizörü ve iyon dedektör sistemi olmak üzere başlıca üç k1sımda incelenebilir.

Ion Max API Kaynağı: Analiz yapılacak numuneye bağlı olarak ESI (Electrospray İyonizasyon) veya APCI (Atmosferik Basınç İyonizasyon Kaynağı) iyonizasyon teknikleri kullanılabilir. Genel olarak aminler, peptidler ve proteinler gibi polar bileşikler ESI tekniği ile steroidler gibi apolar bileşikler ise APCI tekniği ile analiz edilir.

Kütle Analizörü: İyon kaynağından gelen iyonlar, kütle analizöründe değişen elektrik alana tabi tutularak m/z (kütle/yük) oranlarına göre ayrılırlar. Cihazda Ion-Trap kütle analizörü mevcuttur.

MS İyon Dedektör Sistemi: MS dedektörü yüksek duyarlılığa sahip, pozitif ve negatif iyon modlarında çalışan bir iyon dedektör sistemidir.

Mikotoksinlerin analizinde LCMS/MS tekniği oldukça kullanılmaktadır.
LC-MS/MS tekniğinde UPLC cihazı sayesinde fizikokimyasal özelliklerine göre ayrılan örnek molekülleri kütle dedektorü ile analiz edilmektedir. Kütle spektrometreleri molekülleri iyonizasyon işlemi ile uyararak yüklü iyonize moleküller haline dönüştürürler. Birinci kuadrupol filtrede m/z (kütle/yük) oranına göre ayrılan moleküller çarpışma gazı (collision gas) adı verilen yüksek saflıkta özel bir gaz ile (Azot) parçalanmaya tabi tutulmaktadır. İkinci kuadrupol filtrede parçalanma sonucu oluşan iyonların (yavru iyon (daughter ion, product ion)) üzerinden teşhis ve miktar tayini yapılmaktadır [29].

HPLC-MS/MS ve LC-MS/MS mikotoksin ile metabolitlerinin belirlenmesinde çok sık kullanılmaktadır.

Trikotesen ve zearalenon mikotoksinlerinin kantitatif analizinde GCMS başarı ile kullanılmıştır [8; 30]. LC-MS ile çoklu mikotoksin metotları ekstraksiyon ve temizleme basamaklarının optimum şartlarda olmaları yönünden avantajlıdır. Matriks etkisi buradaki önemli sorunlardandır. Bunun önüne geçmenin yolu matriksli standartlar hazırlamak veya toksin/matriks kombinasyonu ile çalışmaktır. Böyle metotlar geleneksel metotlarla karşılaştırıldığında analitik işgücünde büyük bir azalış ve analitik verimde büyük bir artışı sağlar [8; 31]. 
Zhu ve ark. [32] LC-MS/MS ile yumurtalarda çoklu mikotoksin analizi çalışmıştır. Çalıştıkları metot aflatoksinler, deoksinivalenol ve türevleri ile zeralenon ve türevlerini içeren birçok mikotoksini kapsamaktadır. Zhao ve ark. [33] hayvan yemlerinde LC-MS/MS ile çoklu mikotoksin analizi çalışmıştır. Nielsen ve ark. [34] yeşil, öğütülmüş ve hazır kahvelerde okratoksin-A ve fumonisinleri (B2, B4, B6) LC-MS/MS'de asit ve su ile ekstraksiyonuyla çalışmıştır [35].

Fistık ezmesi, pirinç, mısır ve unlarla UPLC-MS/MS ile yapılan bir çalışmada aflatoksin B1, B2, G1 ve G2 için LOQ değerleri $0,25^{\prime}$ er ppb olarak belirtilmiştir [37]. HPLC'ye göre tek seferde pozitif veya negatif modda çok sayıda mikotoksine bakabilme özelliği ile daha üstün olduğu bildirilmiştir.

Direkt elektrosprey tandem kütle spektormetre cihazı ile buğday ve mısırda yapılan bir çalışmada LOQ 2,8 ppb olarak belirtilmiştir [38].

Sonuç olarak mikotoksin analizleri enstrümental olarak çoğunlukla HPLC ve LC-MS/MS ile yapılmaktadır. Tablo 1'de HPLC ve LC-MS/MS karşılaştırılması gösterilmektedir.
Tablo 1. HPLC ve LC-MS/MS 'in genel olarak karşılaş̧tırılması

\begin{tabular}{|c|c|c|}
\hline KONU & HPLC & LC-MS/MS \\
\hline $\begin{array}{c}\text { Kimyasal } \\
\text { sarfiyatı } \\
\text { (numune başı) } \\
\text { (metanol-su, } \\
\text { asetonitril-su, } \\
\text { kloroform-su } \\
\text { karışımları v.b.) } \\
\text { Ekstraksiyon }\end{array}$ & Daha uzun sürede & $\begin{array}{l}\text { Daha kısa } \\
\text { sürede }\end{array}$ \\
\hline $\begin{array}{c}\text { Çoklu } \\
\text { Mikotoksin } \\
\text { Analizleri } \\
\text { (Aflatoksin (B1, } \\
\text { B2, G1, G2), } \\
\text { Okratoksin-A, } \\
\text { Zearalenone, } \\
\text { Deoksinivalenol, } \\
\text { Fumonisin B1 } \\
\text { ve B2, T-2 } \\
\text { toksin, HT-2 } \\
\text { toksin }\end{array}$ & $\begin{array}{c}\text { Ayrı ayrı } \\
\text { immunoaffinite } \\
\text { kolonlar gibi } \\
\text { aparatlar ve ayrı } \\
\text { ayrı } \\
\text { enjeksiyonlarla } \\
\text { yapılabiliyor. }\end{array}$ & $\begin{array}{c}\text { Tek } \\
\text { enjeksiyonda } \\
\text { yapılabiliyor. }\end{array}$ \\
\hline $\begin{array}{c}\text { Metod } \\
\text { Sağlamlığ }\end{array}$ & $\begin{array}{l}\text { Daha eski ve } \\
\text { uluslar aras1 }\end{array}$ & $\begin{array}{l}\text { Daha yeni } \\
\text { oluşturulan } \\
\text { (İşletme içi) }\end{array}$ \\
\hline Ölçüm Limitleri & $\begin{array}{c}\text { Aynı seviyelere } \\
\text { inilebilir } \\
\text { (Kullanılan } \\
\text { cihazın } \\
\text { özellikleri, analizi } \\
\text { yapılan matriks } \\
\text { gibi parametrelere } \\
\text { bağlidır. HPLC } \\
\text { ve LC-MS/MS'in } \\
\text { özelliklerine bağlı } \\
\text { olarak LC- } \\
\text { MS/MS'te daha } \\
\text { düşük seviyelere } \\
\text { inilebilir. Örneğin } \\
\text { aflatoksin B1, B2, } \\
\text { G1 ve G2 için } 0,5 \\
\text { ppb gibi) }\end{array}$ & \\
\hline $\begin{array}{l}\text { Cihaz Maliyeti } \\
\text { ve Arızaları }\end{array}$ & Daha az ve ucuz & $\begin{array}{c}\text { Daha fazla ve } \\
\text { pahalı }\end{array}$ \\
\hline Kolon & $\begin{array}{c}\text { Kullanılan } \\
\text { metoda ve analizi } \\
\text { yapılan toksine } \\
\text { göre olmaktadır. } \\
\text { (Aflatoksinlerde } \\
\text { C18, RP18 } \\
\text { kolonlar v.b.) }\end{array}$ & \\
\hline
\end{tabular}


Aflatoksin Analiz Yöntemlerindeki Son

Gelişmeler

Son y1llarda ise immunoassay metodunun başka bir tipi olan biyosensörlerin kullanımı yaygınlaşmaktadır. Burada da toksin seviyelerinin ölçümünde ve toksinin yakalanmasında antikorlar

kullanılmaktadır. Son zamanlarda bu konuyla ilgili çeşitli araştırmalar yapılmaktadır. $\mathrm{Bu}$ yeni geliştirilen sistemlerin immunoaffinite prensiplerine ve floresans esasına dayandığı bildirilmektedir [8; 39].

Gaag ve ark. [39] HPLC ve ELISA yöntemleriyle karşılaştırmalı olarak biyosensör kullandıkları çalışmada, biyosensörlerin tekrarlanabilirliği, üretilebilirliği gibi özelliklerinden dolayı çoklu mikotoksin aranmasının, tek bir ölçümle yapılmaya çalışıldığı ELISA ve HPLC tekniklerine göre daha iyi olduğunu belirtmişlerdir [8;36]. Arduini ve ark. [40] türevlendirme ya da belirli bir enzim ile işleme gerek olmadan aflatoksin B1'in saptanmasını sağlayan taşınabilir bir fiber optik spektrofotometresi tasarlamıştır. Metodun esası ekstraksiyon ve IAC'ye dayanmaktadır.

Benzer bir şekilde Rasooly ve ark. [41] floresan yoğunluklarını ölçebilen ticari şarjlı birleştirilmiş bir cihaz (CCD) kamerası geliştirmiştir [41; 42]. Wu ve ark. [43] aflatoksin M1 için pratik bir var-yok testi geliştirmiştir. Ancak bu tarz yöntemler validasyon ve doğrulama kavramları için istatistiksel olarak yetersiz kalması dolayısıyla işletme tarzı yerlerde daha etkin olarak kullanılabilir. Huang ve ark. [44] ile Campone ve ark. [45] sütteki aflatoksin M1 için LC-MS metotlarının da kullanılabileceğini, ancak bu yöntem için etkili bir clean-up ve ekstraksiyon işleminin çok önemli olduğu üzerinde durmuşlardır [42; 44; 45]. Tessmer Scaglioni ve ark. [46] aflatoksin B1 için olağandışı bir yaklaşım geliştirmişlerdir. Ekmekteki B1 için bir adsorban olarak pirinç kabuğu önermiştir [42; 46]. Titreşim spektroskopisi alanında Lee ve ark. [47] Fourier dönüşümü (FT), yakın kızılötesi (NIR) ve FT kızılötesi (FTIR) spektroskopisi ile misırdaki aflatoksin B1 düzeylerini tespit etmişlerdir. Araştırmacılar bu yöntemlerin de hızlı ve aflatoksin B1'in gerçek zamanlı izlenmesi için güçlü olduklarını belirtmişlerdir [42; 47].

Sonuç olarak yöntemlerin genel olarak karşılaştırılma yorumu Tablo 2'de verilmektedir. 
Tablo 2. Yöntemlerin Genel Karşılaş̧tırılması

\begin{tabular}{|c|c|c|c|c|c|c|}
\hline $\begin{array}{c}\text { Yöntemler } \\
\text { ve } \\
\text { Özellikler }\end{array}$ & TLC & $\begin{array}{l}\text { Kapiler } \\
\text { Elektroforez }\end{array}$ & ELİSA & HPLC & GC & $\begin{array}{c}\text { Kromatografik } \\
\text { Metotların Kütle } \\
\text { Spektroskopisi ile } \\
\text { Birlikte Kullanımı } \\
\text { (LC-MS/MS, GC- } \\
\text { MS/MS v.b) } \\
\end{array}$ \\
\hline $\begin{array}{c}\text { Kimyasal } \\
\text { sarfiyatı }\end{array}$ & & $\begin{array}{l}\text { Bileşiklerin } \\
\text { elektrik yüklerine } \\
\text { göre ayrımı } \\
\text { yapılır. }\end{array}$ & $\begin{array}{c}\text { Diğer } \\
\text { yöntemlere } \\
\text { göre az } \\
\text { solvent } \\
\text { kullanımı } \\
\end{array}$ & & & $\begin{array}{l}\text { Diğer yöntemlere göre } \\
\text { çok daha az }\end{array}$ \\
\hline $\begin{array}{c}\text { Cooklu } \\
\text { Mikotoksin } \\
\text { Analizleri }\end{array}$ & & & & & & $\begin{array}{l}\text { Tek enjeksiyonda } \\
\text { yapılabilmektedir. }\end{array}$ \\
\hline $\begin{array}{c}\text { Metod } \\
\text { Sağlamlı̆̆ı }\end{array}$ & $\begin{array}{l}\text { Eski ve } \\
\text { artık fazla } \\
\text { kullanılma } \\
\text { maktadır. }\end{array}$ & $\begin{array}{c}\text { Eski ve etkin } \\
\text { olarak } \\
\text { kullanılmamaktad } \\
\text { 1r. } \\
\end{array}$ & Eski & $\begin{array}{c}\text { Eski ve } \\
\text { uluslar } \\
\text { aras1 }\end{array}$ & $\begin{array}{c}\text { Eski ve } \\
\text { uluslar } \\
\text { aras1 }\end{array}$ & $\begin{array}{l}\text { Daha yeni oluşturulan } \\
\text { (İşletme içi metotlar) }\end{array}$ \\
\hline $\begin{array}{c}\text { Cihaz } \\
\text { Maliyeti ve } \\
\text { Arızaları }\end{array}$ & & & & $\begin{array}{l}\text { Düşük } \\
\text { ve az }\end{array}$ & $\begin{array}{l}\text { Düşük } \\
\text { ve az }\end{array}$ & $\begin{array}{c}\text { Daha yüksek ve daha } \\
\text { fazla }\end{array}$ \\
\hline
\end{tabular}

\section{Sonuç}

Mikotoksinlerin saptanması için çeşitli analiz yöntemleri bulunmaktadır. Son zamanlarda kaydedilen başarılı yöntemler olmasına rağmen daha yüksek ölçüde hassasiyeti sağlamak ve toksinlerden dolayı çıkan zorlukları önlemek için hala yeni metotlara ihtiyaç duyulmaktadır.

HPLC metodu aflatoksinlerin belirlenmesinde dünyada en yaygın olarak kullanılan yöntemlerdendir. HPLC'nin yanısıra MS ile kromatografi tekniklerinin (LC-MS/MS gibi) birlikte kullanılması aflatoksinler için ölçüm limitini düşüren ve ön plana çıkan yöntemlerdendir.
Son yıllarda, birçok matriks grubunda özellikle çoklu mikotoksinlerin aynı anda tayininde LC-MS/MS kullanılmaya başlanmıştır. Bununla birlikte, yatırım maliyetinin yüksek olması ve yüksek teknik donanıma sahip personele gereksinim duyulması bu yöntemi sinırlandıran durumlardandir [48]. HPLC ve LC-MS/MS yöntemleri ölçüm limitlerinin düşüklüğü, elde edilen geri kazanım oranlarının yüksekliği ve metot doğrulukları açısından diğer yöntemler arasından rahatlıkla siyrilmaktadır. 


\section{Kaynaklar}

[1] Tiryaki, O., Seçer, E., Temur, C., 2011. Yemlerde Mikotoksin Oluşumu, Toksisiteleri ve Mikotoksin Kalıntı Analizleri. Anadolu 21(1):44-58.

[2] Zinedine, A., González-Osnaya, L., Soriano, J.M., Moltó, J.C., Idrissi, L., Mañes, J., 2007. Presence of Aflatoxin M1 in Pasteurized Milk From Morocco. International Journal of Food Microbiology 114(1):25-9.

[3] Yentür, G., Er, B., 2012. Gıdalarda Aflatoksin Varlığının Değerlendirilmesi. Türk Hijyen ve Deneysel Biyoloji Dergisi 69(1):41-52.

[4] Steyn, P.S., 1998. The Biosynthesis of Mycotoxins. Revista de Medicina Veterinaria 149:469-478.

[5] Döll, S., Dänicke, S., 2011. The Fusarium toxins deoxynivalenol (DON) and zearalenone (ZON) in animal feding. Preventive Veterinary Medicine 102:132145.

[6] Kurdar, S.S., 2006. Süt ve Ürünlerinde Mikotoksinler. Türkiye 9. Gida Kongresi; 24-26 Mayıs 2006, Bolu, Türkiye, s 307310 .

[7] Creppy, E.E., 2002. Update of survey, regulation and toxic effects of mycotoxins in Europe. Toxicology Letters 127:19-28.

[8] Hacıbekiroğlu, I., 2013. Gida Örneklerinde Aflatoksin (G1, G2, B1, B2) ve Okratoksin A'nın HPLC Metot Validasyonu ve Miktar Tayinleri, Doktora Tezi, T.C. İstanbul Üniversitesi Sağlık Bilimleri Enstitüsü, $121 \mathrm{~s}$.
[9] Vidyasagar, T., Sujatha, N., Sashidhar, R.B., 1997. Determination of aflatoxin B1DNA adduct in rat liver by enzyme immunoassay. Analyst 122: 60913.

[10] Busby, W.F.Jr., Wogan, G.N., 1984. Aflatoxins. In: Edwards F, ed. Chemical Carcinogens. Maple Press Co, York.

[11] Türköz Bakırcı, G., 2014. Tahıl ve Tahıl Ürünlerinin Aflatoksin, Okratoksin A, Zearalenon, Fumonisin ve Deoksinivalenol Mikotoksinleri Yönünden İncelenmesi. Akademik Gida 12(2):46-56.

[12] Campbell, K., Cavalcante, A. L. F, Galvin-King, P., Oplatowska-Stachowiak, M., Brabet, C., Metayer, I., Montet, D., Haughey, S. A., Elliott, C. T., 2017. Evaluation of an alternative spectroscopic approach for aflatoxin analysis: Comparative analysis of food and feed samples with UPLC-MS/MS. Sensors and Actuators B 239:1087-1097.

[13] Wall, P.E., 2005. Handbook of ThinLayer Chromatography: A Modern Practical Approach. The Royal Society of Chemistry, Cambridge.

[14] Sherma, J., Friend, B., 2003. Handbook of Thin-Layer Chromatography. Third Edition, Marceldeker Inc, New York.

[15] Karakaş, T., 2013. İnce Tabaka Kromatografisinde Yeni Bir Teknikle Kırmızıbiberde Aflatoksin Tayini, Yüksek Lisans Tezi, T.C. Yüzüncü Y1l Üniversitesi Fen Bilimleri Enstitüsü Gıda Mühendisliği Anabilim Dalı, 73 s.

[16] Turner, N. W., Subrahmanyam, S., Piletsky, S. A, 2009. Analytical methods for determination of mycotoxins: A review. Analytica Chimica Acta 632:168-180. 
[17] Van Egmond, H. P., Paulsch, W. E., Schuller, P. L., 1978. Confirmatory test for aflatoxin M1 on thin layer plate. Journal of AOAC International 61(4):809-812.

[18] http://www.intechopen.com/ Erişim tarihi: 13.05.17

[19] Çoksöyler, N., 1996. Mikotoksinler ve Analiz Yöntemleri (kurs notları, basılmamış). Mersin Üniversitesi, Mersin.

[20] Pena,R., Alcaraz, M.C., Arce, L., Rios, A., Valcarel, M., 2002. Screening of aflatoxins in feed samples using a flow system coupled to capillary electrophoresis. Journal of Chromatography A 967:303-314.

[21] Maragos, C., 1999. New ways to monitor toxins. Agricultural Research, February By Linda McGraw, ARS.

[22] Chu, F.S., 1984. Immunoassays for analysis of Mycotoxins. Journal of Food Protection 47:562-569.

[23] http://www.mikrobiyoloji.org/pdf/702 041101.pdf/ Erişim tarihi: 30.01.18

[24] Valenta,H., 1998. Chromatographic methods for the determination of ochratoxin $\mathrm{A}$ in animal and human tissues and fluids. Journal of Chromatography A 815:75-92.

[25] Hışı1, Y., 1999. Enstrümental Gıda Analizleri (I). Ege Üniversitesi Basımevi, Bornova İzmir, 218.

[26] Scott, P., M., 1995. Mycotoxin methodology. Food Additives \& Contaminants 12:395-403.

[27] Garner, R.C., Whattam, M.M., Taylor, P.J.L., Stow, M.W.,1993. Analysis of United Kingdom purchased spices for aflatoxins using an immunoaffinity column clean-up procedure followed by highperformance liquid chromatographic analysis and post-column derivatisation with pyridinium bromide perbromide. Journal of Chromatography A 648:485490.

[28] Sedefoğlu, C., 2013. Antep Fistıklarında Okratoksin A ve Aflatoksin Varlığının İncelenmesi, Yüksek Lisans Tezi, İstanbul Teknik Üniversitesi Fen Bilimleri Enstitüsü Gıda Mühendisliği Anabilim Dal1, 89s.

[29] https://www.agri.edu.tr/UserFiles/CK Upload/Upload/LC-

MS\%20Cihaz\%20Raporu.pdf/ Erişim tarihi: 30.01 .18

[30] Tanaka, H., Takino, M., SugitaKonishi, Y., Tanaka, T., 2007. Development of a liquid chromatography/time-of-flight mass spectrometric method for the simultaneous determination of trichothecenes, zearalenone and aflatoxins in foodstuffs. Rapid Communications in Mass Spectrometry 20:1422-1428.

[31] Berthiller, F., Schuhmacher, R., Buttinger, G., Krska, R., 2005. Rapid simultaneous determination of major type A- and B-trichothecenes as well as zearalenone in maize by high performance liquid chromatography-tandem mass spectrometry. Journal of Chromatography A 1062:209-216.

[32] Zhu, R., Zhao, Z., Wang, J., Bai, B., Wu, A., Yan, L. and Song, S., 2015. A simple sample pretreatment method for multi-mycotoxin determination in eggs by liquid chromatography tandem mass 
spectrometry. Journal of Chromatography A 1417:1-7.

[33] Zhao, Z., Liu, N., Yang, L., Deng, Y., Wang, J., Song, S., Lin, S., Wu, A., Zhou, Z. and Hou, J., 2015. Multi-mycotoxin analysis of animal feed and animal-derived food using LC-MS/MS system with timed and highly selective reaction monitoring. Analytical and Bioanalytical Chemistry 407:7359-7368.

[34] Nielsen, K.F., Ngemela, A.F., Jensen, L.B., De Medeiros, L.S. and Rasmussen, P.H., 2015. UHPLC-MS/MS determination of ochratoxin A and fumonisins in coffee using QuEChERS extraction combined with mixed-mode SPE purification. Journal of Agricultural and Food Chemistry 63:1029-1034.

[35] Berthiller, F., Brera, C., Iha, M.H., Krska, R., Lattanzio, V.M.T., MacDonald, S., Malone, R.J, Maragos, C., Solfrizzo, M., Stranska-Zachariasova, M., Stroka, J., Tittlemier, S.A., 2017. Developments in mycotoxin analysis: an update for 20152016. World Mycotoxin Journal 10(1):5-29.

[36] Prudente, A.D., 2002. Use of biosensors for rapid screening of aflatoxin. LSU Food Science Graduate Seminar. March 22.Louisiana State University.

[37]Campbell, K., Cavalcante, A.L.F:, Galvin-King, P., Oplatowska-Stachowiak, M., Brabet, C., Isabelle, M., Montet, D., Haughey, S.A., Elliott, C.T., 2017. Evaluation of an alternative spectroscopic approach for aflatoxinanalysis: Comparative analysis of food and feed samples withUPLC-MS/MS. Sensors and Actuators B 239:1087-1097.
[38] Satarpai, T., Siripinyanond, A., Su, H., Shiea, J., 2016. Rapid characterization of trace aflatoxin B1 in groundnuts, wheat and maize by dispersive liquid-liquid microextraction followed by direct electrospray probe tandem mass spectrometry. Rapid Commun. Mass Spectrom., 31, 728-736.

[39] Gaag, B., Edwin, S, Pohl, S., 2000. Multi analyte biosensor for the detection of mycotoxins.

TNO.http://www.nal.usda.gov.htm.

[40] Arduini, F., Neagu, D., Pagliarini, V., Scognamiglio, V., Leonardis, M.A., Gatto, E., Amine, A., Palleschi, G., Moscone. D., 2016. Rapid and label-free detection of ochratoxin A and aflatoxin B1 using an optical portable instrument. Talanta 150: 440-448.

[41] Rasooly, R., Do, P.M., Hernlem, B.J., 2016. Low cost quantitative digital imaging as an alternative to qualitative in vivo bioassays for analysis of active aflatoxin B1. Biosensors and Bioelectronics 80:405410.

[42] Berthiller, F., Brera, C., Iha, M.H., Krska, R., Lattanzio, V.M.T., MacDonald, S., Malone, R.J., Maragos, C., Solfrizzo, M., Stranska-Zachariasova, M., Stroka, J., Tittlemier, S.A., 2017. Developments in mycotoxin analysis: an update for 20152016. World Mycotoxin Journal 10(1):5-29.

[43] Wu, C., Liu, D., Peng, T., Shan, D., Zhang, G., Xiong, Y. and Lai, W., 2016. Development of a one-step immunochromatographic assay with two cutoff values of aflatoxin M1. Food Control 63:11-14. 
[44] Huang, S., Hu, D., Wang, Y., Zhu, F., Jiang, R. and Ouyang, G., 2015. Automated hollow-fiber liquid-phase microextraction coupled with liquid chromatography/tandem mass spectrometry for the analysis of aflatoxin M1 in milk. Journal of Chromatography A 1416:137140.

[45] Campone, L., Piccinelli, A.L., Celano, R., Pagano, I., Russo, M. and Rastrelli, L., 2016. Rapid and automated analysis of aflatoxin M1 in milk and dairy products by online solid phase extraction coupled to ultra-high-pressure-liquid-chromatography tandem mass spectrometry. Journal of Chromatography A 1428:212-219.

[46] Tessmer Scaglioni, P., BadialeFurlong, E., 2016. Rice husk as an adsorbent: a new analytical approach to determine aflatoxins in milk. Talanta 152:423-431.

[47] Lee, H.J. and Ryu, D., 2015. Advances in mycotoxin research: public health perspectives. Journal of Food Science 80:2970-2983.

[48] Kanık, T., 2018. Bademlerde Aflatoksin Varlığının Belirlenmesi, Yüksek Lisans Tezi, Hitit Üniversitesi Fen Bilimleri Enstitüsü Gıda Mühendisliği Anabilim Dal1, 61s. 